\title{
Crises financeiras nos anos 1990 e poupança externa
}

\author{
Luiz Carlos Bresser-Pereira \\ Professor emérito da Fundação Getúlio Vargas \\ Lauro Gonzalez \\ Professor da Fundação Getúlio Vargas em São Paulo \\ Cláudio Lucinda \\ Professor da Fundação Getúlio Vargas em São Paulo
}

\section{Palauras-chave}

crise financeira, crise de balanço de pagamentos, poupança externa, taxa de câmbio.

Classificação JEL F3, F4, F5.

Key words

financial crisis, balance of payment crises, current account deficits, exchange rate.

JEL Classification F3, F4, F5.

\section{Resumo}

Ao contrário do que afirma a análise econômica convencional, a causa principal das crises financeiras dos países emergentes dos anos 1990 e início dos anos 2000s começando pela do México (1994) e terminando com a da Argentina (2001) não foi fiscal, mas a decisão dos governos de promover o crescimento com poupança externa, isto é, com déficits em conta corrente. Como a taxa de câmbio tem outros determinantes além da absorção interna, o pressuposto dos déficits gêmeos com frequência não é válido. Essas foram de balanço de pagamentos e se caracterizaram por elevados déficits em conta corrente e forte aumento da dívida externa e/ou por forte aumento do déficit em conta corrente, que levaram os credores a se persuadirem que o problema do país era ou de liquidez ou de solvência, ou ambos, e decidirem, subitamente, suspender a rolagem da dívida externa do país. Um teste econométrico substancia a hipótese do trabalho.

\section{Abstract}

Contrary to what conventional economic analysis afirms, the main cause of the financial crises in emerging countries during the 1990s, beginning with Mexico (1994) and ending with the crisis in Argentina (2001) was not primarily fiscal, but the decision by governments to foster growth with foreign savings, i.e., with current account deficits. Since the exchange rate has other determinants besides domestic absorption, the assumption of twin deficits often does not hold. These were balance of payment crises triggered by an overvalued local currency and the high increases in the foreign debt and/ or the fast growth of the current account deficit. This led, foreign creditors to suddenly become persuaded that the country faced both liquidity and solvency problems, and to stop rolling over the debt. An econometric test substantiates these claims. 


\section{Introdução}

Os anos 1990 se caracterizaram por uma sucessão de crises financeiras ocorridas em diversos países, sobretudo aqueles denominados como mercados emergentes. $\mathrm{O}$ objetivo deste trabalho é, para os países emergentes, sobretudo latino-americanos e asiáticos, relacionar essas crises à política de crescimento com poupança externa e, em consequência, aos déficits em contacorrente financiados por grandes influxos de capital. O período de análise escolhido inicia-se em 1990 e estende-se até 2002, no entorno da crise argentina. Interessante notar que foram influxos igualmente grandes de capital, nos anos 1970, que, na década seguinte, causaram a grande crise da dívida externa que paralisou o crescimento dos países latino-americanos. Durante os anos 1980, esses influxos foram interrompidos, mas a solução representada pelo Plano Brady devolveu o crédito a esses países, de forma que o excesso de liquidez internacional pudesse voltarse novamente para os países emergentes ou de renda média com a justificativa de que eles não teriam poupança interna para financiar seu desenvolvimento.

A falta de sustentação do pressuposto de falta de poupança interna e consequências negativas da política de crescimento com poupança externa sobre o desenvolvi- mento econômico foram analisadas anteriormente por um dos autores deste trabalho, que, mais recentemente, completou sua teoria propondo a existência nos países em desenvolvimento de uma tendência à sobreapreciação da taxa de câmbio. ${ }^{1}$ Essas consequências estão associadas à apreciação da moeda nacional causada pelo déficit em conta-corrente (poupança externa) financiado por esses influxos. ${ }^{2}$ De um lado, a sobreapreciação do câmbio provoca o aumento artificial dos salários reais e do consumo, e, de outro, desestimula os investimentos voltados para as exportações. $\mathrm{O}$ resultado, em condições normais, é uma elevada taxa de substituição da poupança interna pela externa, ou seja, o desvio dos recursos externos para o consumo mesmo que eles venham para financiar investimentos diretos, e pouco ou nenhum aumento das taxas de poupança e de investimento do país, ao mesmo tempo em que esse aumenta sua dívida externa financeira ou patrimonial. Apenas em circunstâncias extraordinárias, quando o país já está crescendo aceleradamente e as oportunidades de lucro são muito elevadas, essa substituição é pequena na medida em que, nesses momentos, a propensão a consumir da população diminui.

Nesses trabalhos, não havia uma preocupação específica com a explicação das

\footnotetext{
Para a crítica ao crescimento com poupança externa, ver Bresser-Pereira (2002), Bresser-Pereira e Nakano (2002 [2003]), Bresser-Pereira e Gala (2007); sobre a tendência à sobreapreciação da taxa de câmbio, Bresser-Pereira (2008b, 2009, cap. 4).

2 É importante lembrar que um déficit em conta-corrente supõe uma taxa de câmbio mais apreciada do que aquela que equilibraria a conta-corrente do país.
} 
3 Lauro Gonzales (2007).

Para a realização deste trabalho, o autor contou com o apoio econométrico de Cláudio Lucinda. crises financeiras recentes com base no modelo de crítica à política de crescimento com poupança externa. O que se afirmava, apenas, era que o recurso sistemático à poupança externa apenas promove o crescimento econômico quando prevalecem condições especiais, quando o país já está crescendo aceleradamente, e a propensão a consumir da população diminui. Em situações normais, déficits em conta-corrente, em um primeiro momento, causam endividamento externo e substituição da poupança interna pela externa; em um segundo, fragilidade financeira e confidence building, e, em um terceiro, crise de balanço de pagamentos. A relação específica entre crises financeiras de balanço de pagamentos e a política de crescimento com poupança externa foi realizada por um dos autores deste trabalho. ${ }^{3}$ Agora, o que se pretende é, a partir dessas contribuições anteriores, oferecer de forma resumida uma explicação nova para os episódios de turbulência financeira dos anos 1990 até 2002 - uma explicação alternativa às explicações convencionais, as quais, não obstantes suas diferenças e gerações, acabam equivocadamente por atribuir principalmente ao déficit público a causa das crises de balanço de pagamentos que ocorrem nos países em desenvolvimento.

Tais crises de balanço de pagamentos são, essencialmente, consequência de déficits em conta-corrente que levam os credores externos a, de repente, suspender a rolagem dos créditos dados a determinado país. Esses déficits são geralmente acompanhados de alto endividamento externo, que resultam da acumulação de déficits em conta-corrente, mas podem também ser consequência apenas do aumento rápido desses próprios déficits - um fator suficiente para que os credores externos percam a confiança no país. Esses déficits também afetam a capacidade de um país atender às restrições de solvência e liquidez, e, quando essas não são mais atendidas, eclode a crise. A restrição de solvência diz simplesmente que o valor presente dos pagamentos futuros, ou da capacidade futura de pagamentos da dívida, deve ser suficiente para liquidar o estoque atual da dívida. Já a restrição de liquidez diz respeito à capacidade de honrar obrigações de curto prazo. Dessas definições, depreende-se que a solvência é um problema estrutural, ao passo que a liquidez é de natureza conjuntural. Não obstante essas diferenças, a desobediência a ambas, isolada ou conjuntamente, conduz à crise financeira.

A explicação aqui proposta se aplica preponderantemente aos chamados mercados emergentes, já que a esses países se recomendou uma política de abertura financeira que viabilizasse a absorção de re- 
cursos externos, notadamente quando a oferta desses recursos retomou seu ciclo de alta. Portanto, a adoção da estratégia de crescimento com poupança externa parecia constituir a linha de menor resistência para o financiamento do crescimento dos emergentes, sobretudo em um momento de abundância de capitais. A maior parte dos países emergentes que adotaram essa estratégia pertence à América Latina e à Ásia, regiões, por isso mesmo, ponto central deste trabalho.

Cumpre ressaltar que o termo "crise financeira" é amplo e, por isso mesmo, acaba sendo definido de variadas maneiras, conforme o interesse e o foco do estudo. A explicação para a diversidade de definições advém do fato de que uma crise financeira tem inúmeras dimensões, muitas vezes inter-relacionadas. Uma crise financeira pode ser bancária, das contas públicas, corporativa ou empresarial, e de balanço de pagamentos, dependendo de serem os bancos, o setor público, as empresas, ou o país como um todo que subitamente perderam crédito. Neste trabalho, examinaremos as crises de balanço de pagamentos ou crises cambiais dos anos 1990 e início dos anos 2000, sendo esses dois termos associados à crise, doravante adotados de maneira indistinta. Como veremos, nos países que experimentaram crises, é notável a presença de déficits em conta-corrente sucessivos e elevados nos arredores do período de turbulência. Além disso, os dados do período posterior às crises mostram que esses mesmos países apresentaram elevados superávits em conta-corrente e maior controle da taxa de câmbio. É importante assinalar que a adoção da uma política de elevados déficits em conta-corrente pelos países de renda média política foi incentivada pelos organismos multilaterais, especialmente o FMI, que passaram a aconselhar firmemente a adoção da política de crescimento com poupança externa combinada com a abertura financeira.

Este trabalho está organizado em três seções. A primeira discute as explicações convencionais e suas limitações para os episódios de crise. A segunda seção apresenta a ligação entre poupança externa e crises financeiras por meio da deterioração das restrições de solvência e liquidez. A terceira seção investiga empiricamente a ligação entre essas restrições e um índice de pressão cambial, cujo comportamento define a existência de episódios de crise. A última seção contém os comentários finais e a conclusão do trabalho.

\section{1_Explicações convencionais}

As explicações ou modelos da teoria convencional sobre as crises cambiais ocorre- 
ram em três etapas ou "gerações" distintas. Inicialmente, com base em Krugman (1979), uma série de modelos atribuía a crise cambial à incompatibilidade entre as variáveis determinantes da taxa de câmbio e o seu valor fixado pelas autoridades monetárias. Entre essas variáveis, salientava-se o déficit público excessivo. Por exemplo, o Estado fixa a taxa de câmbio e promove uma política fiscal incompatível com a manutenção da paridade cambial. Esses modelos ficaram conhecidos como modelos de primeira geração. Nesse quadro teórico, Miranda (2002) testou uma versão de modelo de primeira geração para o caso brasileiro, tendo como referencial teórico uma adaptação de um dos principais modelos de ataque especulativo de primeira geração por Flood e Garber (1984). O autor estimou os parâmetros da equação de probabilidade de ocorrência de ataques especulativos no Brasil, no período de janeiro de 1982 a janeiro de 1999, tal como concebida no modelo de Ötker e Pazarbasioglu (1995). Os modelos de segunda geração, tais como Obstfeld (1986 e 1994), visavam demonstrar que crises não podem ser identificadas ou preditas somente com base em indicadores macroeconômicos. A desvalorização ou flutuação de uma moeda poderia ser explicada pela realização de profecias autorrealizáveis. Por exemplo, o país poderia experimentar uma típica compensação (trade-off) entre a manutenção do câmbio fixo, sustentado por intermédio de políticas monetárias contracionistas, e a taxa de crescimento do produto.

Assim, no quadro de uma aceleração inflacionária, poderia haver um incentivo ao abandono da paridade cambial se a preferência fosse não sacrificar o produto. Se esse incentivo para o abandono fosse antecipado pelos agentes financeiros, poderia se desencadear uma profecia autorrealizável. Por fim, os modelos de terceira geração, desenvolvidos a partir da crise financeira asiática, recorriam ao argumento de financial excess, conforme desenvolvido em Krugman (1998). Neste caso, a crise financeira seria principalmente de caráter bancário. A linha de raciocínio se inicia com grandes influxos de capital estrangeiro que aumentam a capacidade de empréstimo do sistema bancário local. Essa expansão nos empréstimos é acompanhada por práticas pouco recomendáveis de administração de risco de crédito, fragilizando a carteira dos bancos domésticos.

O pressuposto comum a essa nova família de modelos é a garantia implícita de que os empréstimos de alto risco, em momentos adversos, serão garantidos pelas autoridades monetárias locais. Ou seja, não 
havia incentivo para a prática de uma política de crédito adequada por parte dos bancos, uma vez que se espera bail out em caso de inadimplência. Daí porque os modelos acima se enquadram dentro da chamada visão de risco moral e bolha de ativos. Neste modelo, ter-se-ia um círculo vicioso de expansão de crédito no qual se usam como garantia ativos supervalorizados por bolhas especulativas; a falta de regulação bancária e a certeza de que o Estado não hesitaria em socorrer o sistema seriam os combustíveis desse círculo. Diante do inevitável fim da bolha especulativa no mercado de ativos, a má qualidade dos empréstimos viria à tona, precipitando uma crise bancária. A corrida contra a moeda local surge finalmente, não como causa, mas como consequência do pânico que a crise instaura no mercado financeiro. Tal abordagem desconsidera as práticas bancárias e governamentais nos países em desenvolvimento, enquanto esquece os bancos dos países ricos que financiam os déficits em conta-corrente. As crises financeiras são vistas como crises originalmente bancárias (as crises típicas dos países ricos), e não crises de balanço de pagamentos como de fato são.

Além disso, todos os modelos pressupõem a hipótese dos déficits gêmeos (Gonzáles, 2007). O déficit em transações correntes é visto como resultado líquido de poupança e investimento tanto privada quanto pública e pressupõe-se, contra a evidência empírica, que a taxa de câmbio e o setor privado estão sempre equilibrados. Decisões intertemporais ótimas sobre poupança e investimento, tomadas de maneira descentralizada, produzirão, segundo esses modelos, um balanço em transações correntes igualmente ótimo consistente com uma taxa de câmbio equilibrada intertemporalmente. Se a conta-corrente apontar um déficit, esse também será ótimo, porque derivado de decisões maximizadoras por parte dos agentes. Tudo isso é inconsistente com a relativa autonomia da taxa de câmbio e dos correspondentes déficits em conta-corrente em relação ao déficit público; mais amplamente, é inconsistente com a afirmação de um dos autores deste trabalho de que existe nos países em desenvolvimento uma tendência estrutural à sobreapreciação da taxa de câmbio que só se "resolve" através de crises de balanço de pagamentos (Bresser-Pereira, 2008b, 2009a, cap. 4). ${ }^{4}$

De acordo com esse raciocínio, não há razão para supor que o Estado tenha melhores informações sobre quanto os agentes privados devem poupar ou investir do que esses próprios agentes, não cabendo qualquer tipo de interferência. A exceção se aplica apenas aos déficits em conta-corrente causados pelo excesso de despesa fis-
4 Além disso, esses

pressupostos relativos a decisões racionais e ótimas fazem parte do uso do método hipotético-dedutivo na teoria econômica - um método que um dos autores deste trabalho criticou em outro paper, porque esse método só pode ser a forma principal de raciocínio científico nas ciências metodológicas; nas ciências substantivas como é a economia, o resultado é essencialmente a construção de castelos no ar. O método hipotético é o método adequado senão único para as ciências metodológicas como a matemática e a teoria das decisões (Bresser-Pereira, 2009b). 
5 Ironicamente, no mesmo trabalho, afirma-se que, alguns meses depois, o Reino Unido sofreu grande crise. cal. Enquanto o setor privado pode se endividar sem risco para o país, no caso do endividamento público, o quadro seria diferente porque não se pode supor racionalidade dos agentes públicos. Corden (1994, p. 78) resume a posição acima da seguinte forma:

It follows that an increase in a current account deficit that results from a shift in private sector behavior should not be a matter of concern at all. On the other hand, the public budget deficit is a matter of $p u$ blic policy concern and the focus should be on this $[\ldots]$.

Assim, nos termos dessa concepção teórica convencional, os possíveis efeitos sobre as crises financeiras de déficits em conta-corrente causados por política explícita de crescimento com poupança externa desaparecem. Na raiz de um déficit em conta-corrente de "má qualidade", estaria sempre um problema de desequilíbrio fiscal ou então de determinação dos governos de praticar o risco moral e salvar bancos e empresas a qualquer preço.

Dessas teorias advêm inúmeros desdobramentos, notadamente em forma de adoção e recomendação de política macroeconômica. Em 1981, quando o déficit em transações correntes do Chile atingiu 14\% do PIB, Robischek (1981), então um dos dirigentes mais importantes do FMI, argumentou que não havia motivo para preo- cupação, uma vez que as contas públicas estavam sob controle, e a poupança doméstica se elevava. Alguns meses depois, o Chile viveu uma crise financeira profunda, com grande desvalorização cambial e crise bancária que culminaram com uma queda de 14\% no PIB. Alguns anos adiante, surgiu a chamada "doutrina Lawson", cujo nome se associa à figura de Nigel Lawson, ministro das finanças britânico (1987-1989). De acordo com essa doutrina, não haveria por que se preocupar com os déficits do setor privado, porque esses se reequilibrariam automática e necessariamente; as crises financeiras derivavam sempre do desequilíbrio fiscal do setor público. Reisen (1998, p. 11) cita o seguinte trecho de um discurso proferido por Lawson em setembro de 1988 , tendo em vista comentar as preocupações acerca do balanço de pagamentos do Reino Unido:

We are prisoners of the past, when UK current account deficits were almost invariably associated with large budget deficits, poor economic performance, low reserves and exiguous net overseas assets. The present position could not be more different. ${ }^{5}$

Como se vê, a chamada doutrina Lawson, apesar de não constituir uma teoria de crise, trazia consigo os vários argumentos teóricos que fundem o conceito dos déficits gêmeos com a abordagem inter- 
temporal das contas-correntes. Neste sentido, essa doutrina é emblemática das chamadas teorias convencionais, cuja adoção reflete contextos específicos, como aqueles de alta liquidez no mercado financeiro internacional. Não surpreende, portanto, o momento em que ela foi formulada; ela abria o caminho para a década de 1990 , que foi caracterizada pela política de crescimento com poupança externa, ou seja, de déficits em conta-corrente elevados, e a retomada de fluxos financeiros para os mercados emergentes.

O México constitui um exemplo prático da aplicação da doutrina Lawson. No período 1992-1994, o déficit médio em transações correntes foi de quase 7\% do PIB. Em 1993, o Banco Central do México afirmava:

The current account deficit has been determined exclusively by the private sectors decisions... because of the above and the solid positions of public finances the current account should clearly not be a cause for undue concern (Edwards, 2000, p. 16)

Em resumo, a explicação convencional envolve essencialmente dois elementos, a saber, a teoria dos déficits gêmeos e a visão intertemporal das contas-correntes. $\mathrm{O}$ receituário convencional, contido na doutrina Lawson, nada mais é do que um desdobramento dos dois elementos acima. Sen- do assim, não há nenhuma surpresa na explicação dada pelos modelos convencionais, na medida em que esses compartilham o mesmo suporte teórico sobre o qual a doutrina Lawson se baseia. Entretanto, examinando-se os dados do período aqui estudado, observa-se que inúmeros países, a despeito de equilíbrio nas contas públicas e razoável liberdade de mercado, experimentaram crises de balanço de pagamento. Portanto, as explicações convencionais são insuficientes, e a seção que se segue apresenta uma explicação alternativa para as crises financeiras do período.

\section{2_Poupança externa e crises financeiras recentes}

A crise de balanço de pagamentos desencadeia-se quando os credores externos decidem não mais financiar determinado país e interrompem a rolagem ou renovação de seus débitos. Tal qual no mercado de crédito corporativo, se houver continuidade nas operações de financiamento, os passivos serão renovados, garantindose assim o funcionamento das atividades mesmo que essas não sejam eficientes no sentido de ser capazes de produzir repagamento tanto no curto quanto no longo prazo.

A decisão do credor de continuar a rolar a dívida ou exigir seu pagamento é 
6 Ignora-se aqui a taxa de recuperação, qual seja, a parcela do empréstimo recuperada pós-inadimplência. condicionada pelo retorno esperado das operações. Quando esse retorno se torna negativo, haverá ruptura nos fluxos de financiamento. $\mathrm{O}$ que o credor faz é estimar a probabilidade de receber o valor que lhe é devido (não-inadimplência). Chamando $P$ esta probabilidade de sucesso, o retorno $(R)$ esperado de um credor, que tenha emprestado um montante $K$, a uma taxa $i$, pode ser escrito de maneira simplificada ${ }^{6}$ como:

$E[R]=P \cdot[K(1+i)]-K\left(1+i^{*}\right)$

Onde $i^{*}$ é a taxa de juros internacional que representa o custo de captação do credor. Dado um diferencial de juros positivo $\left(i-i^{*}>0\right)$, a probabilidade $P$ determinará o sinal do retorno esperado do credor. A probabilidade $P$ depende das condições de liquidez e solvência do país. Essas condições podem se deteriorar rapidamente - ou serem percebidas como tendo se deteriorado - de maneira a gerar um retorno esperado negativo para o credor. A eclosão da crise propriamente dita decorre, portanto, do não-atendimento dessas duas restrições fundamentais:

i. restrição de solvência; e

ii. restrição de liquidez.

Quando um país adota como a política de crescimento com o uso de poupança externa, passa a incorrer em déficits em conta-corrente elevados e contínuos que elevam sua dívida externa, tanto pública como privada. Em decorrência, haverá efeitos negativos sobre essas duas restrições e, em consequência, o país tenderá a se tornar frágil financeiramente e, afinal, entrar em crise.

Trata-se, portanto, de uma explicação que traz à tona a importância dos fundamentos do setor externo da economia, ao contrário da abordagem convencional, que se baseia nos fundamentos internos, notadamente, aqueles ligados às contas do governo.

A restrição de solvência intertemporal de um país é similar àquela enfrentada por empresas tradicionais, quando essas recorrem a capital de terceiros. Os credores, a fim de aprovar a operações, vão avaliar a capacidade de pagamento da empresa em relação à sua dívida. A capacidade de pagamento para as empresas nada mais é do que a geração potencial de caixa de seus investimentos (definidos como os ativos operacionais) trazida a valor presente. Diz-se que uma empresa é insolvente quando esse valor presente não é suficiente para honrar seus passivos, entre eles, o endividamento.

Quando se transporta esse raciocínio para a solvência externa de um país, a medida adequada de capacidade de pagamento é o valor presente das transferências futuras de recursos, calculada com base no saldo de exportação menos importação de 
bens e serviços não-fatores. Daí a restrição intertemporal de solvência ser expressa da seguinte forma:

$(1+i) D_{S-1}=\sum_{S=t}^{\infty}\left[\frac{1}{1+i}\right]^{S-t} \operatorname{TLR}_{S}$

Portanto, esse saldo está para um país assim como a geração operacional de caixa está para uma empresa e a insolvência do primeiro, num instante qualquer, é a situação-limite na qual o valor presente das transferências (TLR) não é suficiente para liquidar o estoque de dívida $(D)$ existente naquele mesmo instante.

Entretanto, o conceito de restrição solvência intertemporal stricto sensu é de pouca serventia para um credor porque, a rigor, há infinitas trajetórias possíveis que garantem a solvência intertemporal de um país. Portanto, é preciso observar, entre aquelas possíveis, quais são as trajetórias convencionalmente desejadas pelos credores e que permitem a continuidade na renovação das operações de financiamento. Somente desta forma a restrição de solvência adquire relevância para a compreensão das razões pelas quais os credores podem interromper as operações, potencializando a ocorrência de crises financeiras.

Convencionalmente, utiliza-se a relação entre dívida externa e exportações $(D / X)$ a fim de monitorar a solvência.
Considera-se a posição de um país nesse indicador como confortável se essa relação estiver abaixo de 2; em posição duvidosa, se estiver entre 2 e 4; e em posição crítica, se estiver além de 4. Esses números são, obviamente, uma "regra de bolso" frequentemente utilizada para fins decisórios. A questão passa a ser como a política de uso da poupança externa afeta a relação $D / X$. A política de crescimento com poupança externa afeta negativamente essa relação porque um déficit em conta-corrente é consistente como uma moeda local mais apreciada do que aquela que equilibra a conta-corrente do país, de forma que, quando o déficit em conta-corrente aumenta, a relação $D / X$ aumenta.

A segunda restrição financeira - a de liquidez - define-se pelo descasamento entre a demanda por divisas e o estoque de reservas do Banco Central (BC). O acúmulo de déficits em contas-correntes acaba por provocar esse descasamento entre a demanda potencial de dólares visualizada no balanço patrimonial das instituições financeiras locais (IFs locais) e as reservas internacionais registradas no balanço patrimonial do BC. Nesta análise, os bancos locais e o BC são as duas unidades financeiras fundamentais, que passam de hedge a especulativas no decorrer do ciclo de absorção de poupança externa. ${ }^{7}$

7 A nomenclatura bedge,
especulativo e Ponzi é de
Minsky (1986). Uma unidade
financeira (no caso, um país) é
considerada hedge se tem uma
posição de passivos
financeiros externos muito
reduzida se comparada aos
seus ativos denominados em
moeda estrangeira. No caso
especulativo, o país não tem
essa folga e vai depender
sempre da boa vontade dos
credores em renovar ou rolar
seus créditos. No caso Ponzi,
a situação é de insolvência.


A $\cdots$

8 Ao estabelecer essa

condição, estamos, ao contrário do que afirma a teoria econômica

convencional, a alternativa

"fix or float" não é

empiricamente verdadeira.

Taxas de câmbio são em

diversos graus administradas, e a definição formal de que a taxa é flutuante ou flexível não impede crises de balanço de pagamentos (Bresser-Pereira, 2004).

As crises recentes no Brasil de 2002 e de 2008 são duas das inúmeras confirmações desse pressuposto.

9 Os termos "IFs locais" e "bancos locais" serão usados indistintamente.
Os pressupostos adotados para compreender o papel da restrição de liquidez nas crises de balanço de pagamentos, adequados ao contexto recente dos países em estudo, são:

i. uma taxa de câmbio relativamente fixa ou então flutuante, mas que não responde imediatamente às variações do mercado; 8

ii. crescente grau de abertura financeira internacional por parte dos países.

Além disso, é preciso levar em consideração a conhecida equação de arbitragem entre mercados em que o retorno esperado $(r)$ é igual à taxa de juros internacional $\left(r_{f}\right)$, que constitui o custo de funding, acrescida da expectativa de desvalorização da moeda local (e e e do prêmio de ris$\operatorname{co}(p)$

$r=r_{f}+e+p$

Com os pressupostos acima, importa avaliar o impacto da estratégia de crescimento com poupança externa sobre a liquidez, sendo esta última medida pelo descasamento entre a demanda potencial por divisas e o estoque de reservas do BC. De maneira semelhante à descrita por Neftci (2002), o processo de endividamento externo, acompanhado por apreciação do câmbio, coincide com os momentos iniciais do ciclo de liquidez. Começando pelas IFs locais, ${ }^{9}$ o processo de abertura financeira aumenta a taxa de inovação financeira e a oferta de produtos diferenciados para os diversos aplicadores de recursos.

A remoção das barreiras aos movimentos de capital permite às IFs locais captar recursos em moeda estrangeira, que são vendidos ao $\mathrm{BC}$, e a contrapartida é investida em títulos e/ou gera ativos contra o próprio setor privado. Do ponto de vista sistêmico, os volumes iniciais captados são reduzidos, e a estrutura patrimonial consolidada das IFs locais e do BC é pouco afetada. Com o decorrer do tempo, os retornos obtidos incentivam a entrada de novas instituições, que se posicionam na atividade de captação de recursos em moeda externa e repasse em moeda local, fazendo com que os balanços patrimoniais das IFs locais apresentem características típicas de unidades financeiras especulativas.

Para entender por que isso ocorre, é necessário atentar para a evolução do balanço do $\mathrm{BC}$, que reflete o momentum de mercado, caracterizado por entradas de capital superiores aos déficits (crescentes) nas contas-correntes, o que propicia aumento de ativos em forma de reservas internacionais e reforça a falsa percepção de menor vulnerabilidade externa. $\mathrm{O}$ acúmulo de reservas pode ser acompanhado de aumen- 
tos na oferta monetária, dependendo do grau de intervenção ou esterilização promovido pela autoridade monetária. No caso de expansão da oferta monetária, convencionalmente se argumenta que a queda na taxa de juros doméstica diminuiria o incentivo para a continuidade das operações de captação externa, interrompendo ou abrandando o ciclo de entrada de capital. Essa seria uma solução típica de um mercado eficiente. O que se verifica, entretanto, é que, com o aumento do risco sistêmico, o prêmio de risco acima definido tende a crescer, aumentando o incentivo ao movimento de captação externa.

Obviamente, os credores externos acompanham os níveis (elevados) de endividamento e, em certo momento, são acionadas as chamadas red flags, ou sinais de alerta. A partir de então, as operações passam a ser preponderantemente renovadas, ou seja, não há mais entrada líquida de recursos, e o ciclo de euforia se encerra. Como existe um déficit em conta-corrente a ser financiado, seguindo Neftci (2002), passa a existir um descasamento entre os valores dos compromissos em moeda externa das IFs e as reservas. Em outras palavras, o balanço patrimonial de IFs passa a exibir características tipicamente especulativas.

Seria razoável supor que o $\mathrm{BC}$ poderia interferir de alguma maneira no mer- cado. Isso não acontece em razão do risco sistêmico. A fragilidade do balanço dos bancos locais, majoritariamente composto por unidades especulativas, acaba impondo restrições ao comportamento do BC, em uma configuração tipicamente conhecida como too big to fail. Por outro lado, a economia nacional está na fase expansiva do ciclo econômico. Por isso, embora os credores externos conheçam os incentivos e as restrições do Banco Central, eles são também influenciados pela euforia reinante. Em consequência, o cenário mais provável será o de que a moeda nacional permanecerá sobreapreciada por um longo tempo, levando-a, assim, à crise financeira.

Uma vez que a captação líquida de recursos externos deixa de ser suficiente para financiar o déficit em contas-correntes, a variação das reservas internacionais passa a ser negativa. Sobretudo para o BC, uma variação de reservas negativa implica um balanço patrimonial inequivocamente especulativo. Isso porque, anteriormente, havia a percepção de que eventuais liquidações de operações de captação de recursos externos eram asseguradas pelo estoque (crescente) de reservas internacionais. Agora, em uma situação de reversão de posição, o fluxo de moeda estrangeira potencialmente demandada para financiar os passivos presentes nos balanços dos bancos locais é 
10 Para uma breve discussão sobre as principais definições de crise e os respectivos resultados empíricos, ver Gonzalez (2007).

11 Argentina, Brasil, Equador, Filipinas, Coreia do Sul, México, Peru, República Tcheca, Rússia, Singapura, Tailândia e Venezuela.

12 Ver detalhes em Pereira e Seabra (2004, p. 6 e 7). maior do que aquele presente sob forma de reservas internacionais, no ativo do BC. Basta um credor liquidar total ou parcialmente sua posição, a fim de que se desencadeie um movimento de manada no sentido oposto àquele descrito inicialmente, eclodindo a crise. É importante ressaltar que a hipótese aqui subjacente é que os fundamentos relacionados à solvência e liquidez externas da economia são a causa da crise.

Os argumentos aqui expostos podem ser sintetizados da seguinte forma: a recorrência à poupança externa significa, por definição, acúmulo de déficits em contacorrente. $\mathrm{O}$ endividamento externo crescente, derivado do acúmulo de déficits em conta-corrente, deteriora as restrições de solvência e de liquidez, que são monitoradas pelos credores a fim de decidir a aprovação ou renovação de operações. Quando se torna afinal claro para os credores que essas restrições não são atendidas, eclode a crise.

\section{3_Análise empírica}

Esta seção visa examinar empiricamente a relação entre as condições de solvência e liquidez, deterioradas pelo recurso à poupança externa, e a ocorrência de crises financeiras. Conforme já estabelecido, o foco deste trabalho são os países emergentes, sobretudo da América Latina e da Ásia, no período 1990-2002. Sabe-se que, no mundo real, a identificação de crises financeiras é mais complexa do que nas simplificações teóricas. Portanto, as conclusões e os resultados dos diversos estudos econométricos devem ser condicionados às próprias definições previamente adotadas, e os critérios de definição de crise merecem especial menção. ${ }^{10}$

Conforme salientado ao final da seção anterior, a explicação aqui proposta atribui aos fundamentos do setor externo da economia, deteriorados pela política de recorrer à poupança externa, a ocorrência das crises financeiras no período estudado. Assim sendo, o ponto de partida da análise aqui empreendida é o modelo de Pereira e Seabra (2004), que constitui uma extensão dos modelos de primeira geração, conhecidos na literatura de crise pela explicação baseada nos fundamentos, aplicados a um ambiente de maior vulnerabilidade do setor bancário local. Os autores estimam um índice de Pressão no Mercado Cambial (PMC), para uma amostra de 12 países emergentes, ${ }^{11}$ no período de janeiro de 1995 a dezembro de 2000, utilizando dados trimestrais.

No modelo, a tentativa de socorrer as instituições com dificuldades de liquidez e/ou solvência, por parte do BC, será contraproducente, ${ }^{12}$ dado o impacto negativo 
sobre os gastos fiscais e a política monetária. Se a turbulência financeira, por exemplo, produzir uma deterioração do risco de crédito, são agravados os problemas de inadimplência, reduzindo o estímulo aos depósitos de prazos mais longos. O BC aumenta o crédito concedido ao sistema bancário, contudo, caso os investidores percebam que as reservas internacionais não são suficientes para garantir as exigibilidades de curto prazo dos bancos, a expectativa de depreciação do câmbio aumenta justamente em decorrência do próprio auxílio do BC. Além disso, corridas bancárias ocasionam uma queda brusca das reservas internacionais e aumento das taxas de inflação. O agravamento da situação de fragilidade bancária, por causa da volatilidade cambial, realimenta a necessidade de socorro do Banco Central ao setor bancário, completando-se assim um círculo vicioso e um quadro típico de crise.
Para uma estimação inicial, não há uma definição formal sobre o que constituiria um evento de crise, mas sim o pressuposto de que grandes oscilações (para cima) no chamado índice de pressão cambial seriam indicativos de episódios de crise.

A variável dependente PMC é definida da seguinte forma:

$P M C_{i, t} \equiv \frac{\% \Delta S_{i t}}{\sigma^{S}}+\frac{\% \Delta\left(i_{i, t}-i_{U S A, t}\right)}{\sigma^{i}}-\frac{\% \Delta R_{i, t}}{\sigma^{R}}-\frac{\% \Delta B}{\sigma^{B}}$

O Quadro 1 define cada uma das variáveis acima, sendo que o símbolo $\sigma$ representa, como habitual, o desvio-padrão para cada uma das séries. A fonte dos dados é a base IFS (International Financial Statistics).

Seguindo Pereira e Seabra (2004), em um primeiro passo, serão utilizadas as variáveis explicativas (independentes) descritas no Quadro 2.

\section{Quadro 1_Definição da variável dependente PMC}

\begin{tabular}{|c|c|}
\hline$\% \Delta S$ & Variação percentual na taxa de câmbio nominal. \\
\hline$\% \Delta\left(i_{i, t}-i_{U S A, t}\right)$ & $\begin{array}{l}\text { Variação percentual do diferencial de taxas de juros sobre depósitos } \\
\text { (doméstica versus americana). }\end{array}$ \\
\hline$\% \Delta R_{i}$ & Variação percentual das reservas internacionais. \\
\hline$\% \Delta B$ & Variação percentual do valor de depósitos nominais. \\
\hline
\end{tabular}

Fonte: IFS (International Financial Statistics) e elaboração dos autores. 


\section{Quadro 2_Definição das variáveis independentes}

\begin{tabular}{|c|c|}
\hline II & Constante de cada unidade do painel. \\
\hline$S P$ & Superávit Público Nominal em relação ao PIB do trimestre (IFS). \\
\hline$C B$ & $\begin{array}{l}\text { Crédito das Autoridades Monetárias ao setor bancário em relação ao PIB } \\
\text { do trimestre (IFS). }\end{array}$ \\
\hline$M$ & $\begin{array}{l}\text { Exigibilidades de curto prazo do Banco Central (M2) em relação às reservas } \\
\text { internacionais em dólares (IFS). }\end{array}$ \\
\hline CPMC & $\begin{array}{l}\text { Variável de contágio. É uma média aritmética do índice de Pressão Cambial } \\
\text { de todos os países da amostra, com exceção do próprio país. }\end{array}$ \\
\hline$R P \%$ & $\begin{array}{l}\text { Variação percentual do Risco Político, calculado segundo } \\
\text { o International Country Risk Guide (ICRG). }\end{array}$ \\
\hline$\varepsilon_{i t}$ & Termo de erro. \\
\hline$D$ & Indicação de primeira diferença da variável. \\
\hline
\end{tabular}

Fonte: Elaboração dos autores.

A equação a seguir descreve o modelo geral de estimação. Valores positivos do índice representam um aumento da expectativa futura de depreciação cambial.

$$
\begin{aligned}
P M C_{i t}= & I_{t}+\beta_{1} D S P_{i t}+\beta_{2} D C B_{i t}+\beta_{3} D M_{i t}+\beta_{4} C P M C_{i t}+ \\
& +\beta_{5} R P \%_{i t}+\varepsilon_{i t}
\end{aligned}
$$

Pereira e Seabra (2004) estimaram o modelo por dois métodos: o LSDV (Least Square Dummy Variable) e o GMM (Generalized Method of Moment). Este último dividiu-se em umas duas versões, utilizando uma ou duas defasagens das variáveis incluídas como instrumentos (aqui denominadas GMM1 e GMM2, respectivamente).
Os diferentes métodos apresentaram resultados semelhantes, e a primeira diferença das exigibilidades de curto prazo em relação às reservas (DM) e a pressão cambial média dos outros países da amostra $(C P M C)$ foram significantes a menos de $1 \%$. A variação do crédito do Banco Central ao setor bancário (DCB) foi significante ao nível de $5 \%$, ao passo que a variação percentual do Risco Político ( $R P \%$ ) foi significante a $5 \%$ pelo método LSVD e a $10 \%$ pelo GMM. Já a primeira diferença do Superávit Público Nominal (DSP) foi considerada não significativa em todas as estimativas e para todos os níveis de significância con- 
vencionais, embora tenha apresentado sinal negativo, como esperado pela teoria.

Ademais, todas as variáveis apresentaram sinal condizente com o esperado pela teoria econômica. Os testes Wald, que verificam a significância global dos parâmetros e dummies individuais, apresentaram, tanto para $I$ quanto para $\beta$, significância estatística a menos de $1 \%$. Dessa forma, como apontam os autores, os resultados indicam que as variáveis do modelo, com exceção da variável fiscal (SP), são relevantes para explicar o índice de Pressão Cambial (PMC).

Dada a argumentação teórica anterior, o foco da análise aqui empreendida é investigar empiricamente a hipótese de que a deterioração das condições de solvência e liquidez, advinda do recurso à poupança externa, é capaz de explicar os eventos de crise nos países emergentes, sobretudo da Ásia e da América Latina, para o período compreendido entre 1990 e 2002. Mantido o índice de Pressão Cambial (PMC) como variável dependente, o primeiro passo será a inclusão, no modelo geral (Quadro 1), de variáveis independentes que capturem os fundamentos ligados à liquidez e à solvência.

Os dados utilizados para as estimativas são trimestrais, e a amostra de países foi gerada valendo-se da classificação publicada pelo Financial Times (Country Classification- setembro de 2006). Nessa classificação, 24 países são considerados emergentes. Partindo desse número, tendo em vista o foco na América Latina e na Ásia e a disponibilidade de dados, a amostra resultante foi de 14 países, ${ }^{13}$ a saber: Argentina, Brasil, Coreia do Sul, Equador, Filipinas, Indonésia, Israel, México, Peru, República Tcheca, Rússia, Tailândia, Turquia e Venezuela.

\section{Modelos LSDV e GMM: resultados obtidos}

As Tabelas 1 e 2 apresentam os resultados das estimativas utilizando dois métodos alternativos, o LSDV (Least Square Dummy Variable) e o GMM (Generalized Method of Moment). Inicialmente, na Tabela 1, considera-se o período compreendido entre janeiro de 1995 e dezembro de 2000, replicando o período mais curto de Pereira e Seabra (2004). Na sequência, são apresentados os resultados para o período de real interesse deste trabalho: 19902002. Além disso, incorpora-se ao modelo estimado a variação (VCCEX) ou o próprio saldo em conta-corrente (CCEX), sendo que a letra "L" é indicativo de defasagem por um período (por exemplo, VCCEX defasada um período torna-se LVCCEX). Incorpora-se ainda a variação da relação entre dívida de curto prazo e reservas internacionais (DIVRES). No caso desta variável, utilizou-se a definição de dívida de curto prazo do Banco Mundial.
13 Esta amostra, comparada a Pereira e Seabra (2004), exclui Singapura e inclui Indonésia, Israel, Turquia. 
Tabela 1_Estimação inicial para o período 1995-2000

\begin{tabular}{|c|c|c|}
\hline Dependente: PMC & Modelo LSDV & Modelo GMM1 \\
\hline DSP & $\begin{array}{l}-2.259 \\
(-0.443)\end{array}$ & $\begin{array}{l}-3.973 \\
(-0.977)\end{array}$ \\
\hline DCB & $\begin{array}{l}22.158^{\mathrm{b}} \\
(2.636)\end{array}$ & $\begin{array}{c}23.057^{\mathrm{b}} \\
(3.043)\end{array}$ \\
\hline СРMC & $\begin{array}{l}0.253^{\mathrm{a}} \\
(2.060)\end{array}$ & $\begin{array}{l}0.293^{\mathrm{a}} \\
(2.567)\end{array}$ \\
\hline VARGOV & $\begin{array}{l}-0.000^{c} \\
(-3.365)\end{array}$ & $\begin{array}{l}-0.000^{c} \\
(-4.990)\end{array}$ \\
\hline LVCCEX & $\begin{array}{c}-0.056 \\
(-1.832)\end{array}$ & $\begin{array}{c}-0.048 \\
(-1.721)\end{array}$ \\
\hline DIVRES & $\begin{array}{l}4.346^{c} \\
(3.624)\end{array}$ & $\begin{array}{l}5.083^{c} \\
(4.782)\end{array}$ \\
\hline Constante & $\begin{array}{l}-4.486^{c} \\
(-3.772)\end{array}$ & $\begin{array}{l}-4.923^{c} \\
(-4.529)\end{array}$ \\
\hline N-Obs & 190 & 188 \\
\hline R-sq & $\begin{array}{c}0.356 \\
\mathrm{~F}(6,175)=7,21\end{array}$ & $\begin{array}{c}0.435 \\
\mathrm{~F}(14,173)=11,07\end{array}$ \\
\hline Prob $>$ F & Prob > F 0.0000 & Prob $>$ F 0.0000 \\
\hline
\end{tabular}

(a) Significativo a $5 \%$; (b) Significativo a $1 \%$; (c) Significativo a $0,1 \%$.

Fonte: Elaboração dos autores. 
Tabela 2_Estimação inicial para o período 1990-2002

\begin{tabular}{|c|c|c|c|}
\hline Dependente: PMC & Modelo LSDV & Modelo GMM1 & Modelo GMM2 \\
\hline DCB & $\begin{array}{l}8.204^{\mathrm{a}} \\
(2.208)\end{array}$ & $\begin{array}{l}12.267^{\mathrm{c}} \\
(4.241)\end{array}$ & $\begin{array}{l}14.326^{\mathrm{c}} \\
(5.129)\end{array}$ \\
\hline СРMC & $\begin{array}{l}0.453^{c} \\
(4.105)\end{array}$ & $\begin{array}{l}0.437^{\mathrm{c}} \\
(4.640)\end{array}$ & $\begin{array}{l}0.357^{\mathrm{c}} \\
(3.895)\end{array}$ \\
\hline VARGOV & $\begin{array}{l}-0.000^{c} \\
(-3.872)\end{array}$ & $\begin{array}{l}-0.000^{c} \\
(-4.259)\end{array}$ & $\begin{array}{l}-0.000^{c} \\
(-4.197)\end{array}$ \\
\hline L.VCCEX & $\begin{array}{l}-0.015^{a} \\
(-2.423)\end{array}$ & $\begin{array}{c}-0.013 \\
(-1.828)\end{array}$ & $\begin{array}{l}-0.014^{\mathrm{a}} \\
(-2.272)\end{array}$ \\
\hline DIVRES & $\begin{array}{l}4.742 c \\
(6.412)\end{array}$ & $\begin{array}{l}4.830 \mathrm{c} \\
(6.817)\end{array}$ & $\begin{array}{l}4.738 c \\
(6.774)\end{array}$ \\
\hline Constante & $\begin{array}{l}-4.975^{c} \\
(-6.876)\end{array}$ & $\begin{array}{l}-4.614^{c} \\
(-6.935)\end{array}$ & $\begin{array}{l}-4.598^{c} \\
(-6.876)\end{array}$ \\
\hline $\mathrm{N}-\mathrm{Obs}$ & 426 & 416 & 405 \\
\hline R-sq & $\begin{array}{c}0.364 \\
F(5,410)=16.50\end{array}$ & $\begin{array}{c}0.410 \\
F(15,400)=13.62\end{array}$ & $\begin{array}{c}0.392 \\
F(15,389)=14.69\end{array}$ \\
\hline Prob $>$ F & Prob > F 0.0000 & Prob > F 0.0000 & Prob $>$ F 0.0000 \\
\hline
\end{tabular}

(a) Significativo a $5 \%$; (b) Significativo a $1 \%$; (c) Significativo a $0,1 \%$.

Fonte: Elaboração dos autores. 
As duas variáveis acima visam capturar as restrições de solvência (LVCCEX) e liquidez (DIVRES). A hipótese fundamental é a de que VCCEX e DIVRES são capazes de explicar a pressão no mercado cambial (PMC), e os sinais esperados para os coeficientes são, respectivamente, negativo e positivo. Ou seja, aumentos de VCCEX significam maior saldo em conta-corrente em relação às exportações e menor PMC. De maneira semelhante à relação entre a dívida externa e as exportações (D/X), VCCEX capturaria a solvência. Por outro lado, aumentos de DIVRES significam maior estoque de dívida de curto prazo em relação às reservas internacionais, com efeitos negativos sobre a liquidez, o que aumenta PMC.

Na Tabela 1, para o caso GMM, testou-se unicamente a inclusão de uma defasagem das variáveis incluídas no modelo como instrumentos (GMM1). Os sinais dos coeficientes são esperados, e merece destaque o fato de a variável fiscal (SP) não ser significativa em nenhum dos casos, mesmo ao nível de 10\%. Esse resultado está em consonância com o obtido por Pereira e Seabra (2004). A variável relativa à restrição de liquidez (DIVRES) é significativa a $0,1 \%$ nos dois modelos estimados. Quanto à variável relativa à restrição de solvência (LVCCEX), há significância para um nível de $10 \%$. Os testes indicam haver significância global dos parâmetros a menos de $0,1 \%$. O coeficiente de determinação, para o modelo LSDV, apresenta relativa melhora quando comparado aos resultados originais dos autores acima.

A Tabela 2 apresenta os resultados para o período 1990-2002. Os sinais dos coeficientes estão em conformidade com as expectativas. No modelo LSDV, todas as variáveis instrumentais são significativas a $5 \%$. Nas duas versões GMM, os resultados, em termos de significância dos coeficientes estimados, são semelhantes, à exceção daquele relativo à variável VCCEX na versão GMM1. Mesmo nesse caso, contudo, essa variável é significante ao nível de $10 \%$. Os testes indicam haver significância global dos parâmetros a $0,1 \%$. Cumpre notar que a variável fiscal não está presente na Tabela 2. Isso decorre dos argumentos teóricos anteriormente apresentados.

O próximo passo do protocolo de análise econométrica aqui exposto é a inclusão de variáveis macroeconômicas que desempenhem o papel de controle, tendo em vista seu possível efeito sobre a variável explicativa. A literatura disponível subsidia esse procedimento, e vários estudos destacam as principais variáveis de controle, como é o caso de Eichengreen et al. (1994) e Radelet e Sachs (1998). Foram introduzidos os controles "crédito bancário ao setor privado como porcentagem do PIB" (CREDIT) 
e "variação da inflação ao consumidor" (VARCPI) e a taxa de desemprego (UR). Os resultados estão apresentados na Tabela 3.

Os números apresentados evidenciam que a introdução de variáveis macroeconômicas melhora a significância da variável associada à restrição de solvência. Ressalte-se que, para essa restrição, utilizou-se a relação defasada entre o saldo de transações correntes e as exportações (LCCEX). Controladas, simultaneamente, pelas três variáveis macroeconômicas, LCCEX e DIVRES são significantes ao nível de 1\%, em todos os métodos de estimação. Os controles têm o sinal esperado e, entre as variáveis recém-introduzidas, merece destaque o crédito bancário ao setor privado como porcentagem do PIB (CREDIT).

Tabela 3_Estimação com a inclusão de variáveis macroeconômicas

\begin{tabular}{|c|c|c|c|}
\hline Dependente: PMC & Modelo LSDV & Modelo GMM1 & Modelo GMM2 \\
\hline $\mathrm{DCB}$ & $\begin{array}{c}7.646 \\
(1.644)\end{array}$ & $\begin{array}{l}11.354^{\mathrm{b}} \\
(3.165)\end{array}$ & $\begin{array}{l}15.448^{\mathrm{c}} \\
(4.783)\end{array}$ \\
\hline СРMC & $\begin{array}{l}0.404^{\mathrm{c}} \\
(3.831)\end{array}$ & $\begin{array}{l}0.374 \mathrm{c} \\
(3.872)\end{array}$ & $\begin{array}{l}0.355^{c} \\
(3.786)\end{array}$ \\
\hline VARGOV & $\begin{array}{l}-0.000^{c} \\
(-5.049)\end{array}$ & $\begin{array}{l}-0.000^{c} \\
(-5.357)\end{array}$ & $\begin{array}{l}-0.000^{c} \\
(-5.438)\end{array}$ \\
\hline DIVRES & $\begin{array}{l}3.969^{c} \\
(5.186)\end{array}$ & $\begin{array}{l}4.049^{\mathrm{c}} \\
(5.607)\end{array}$ & $\begin{array}{l}3.735^{\mathrm{c}} \\
(5.510)\end{array}$ \\
\hline LCCEX & $\begin{array}{l}-0.012^{\mathrm{b}} \\
(-2.856)\end{array}$ & $\begin{array}{l}-0.010^{\mathrm{b}} \\
(-2.720)\end{array}$ & $\begin{array}{l}-0.012^{\mathrm{c}} \\
(-3.381)\end{array}$ \\
\hline CREDIT & $\begin{array}{l}0.028 \mathrm{~b} \\
(3.060)\end{array}$ & $\begin{array}{l}0.020^{\mathrm{a}} \\
(2.302)\end{array}$ & $\begin{array}{l}0.018^{\mathrm{a}} \\
(2.207)\end{array}$ \\
\hline VARCPI & $\begin{array}{c}0.057 \\
(1.727)\end{array}$ & $\begin{array}{c}0.057 \\
(1.815)\end{array}$ & $\begin{array}{c}0.052 \\
(1.713)\end{array}$ \\
\hline UR & $\begin{array}{l}0.160^{\mathrm{a}} \\
(2.215)\end{array}$ & $\begin{array}{c}0.087 \\
(1.282)\end{array}$ & $\begin{array}{c}0.070 \\
(1.021)\end{array}$ \\
\hline Constante & $\begin{array}{l}-6.844^{c} \\
(-6.615)\end{array}$ & $\begin{array}{l}-6.147^{\mathrm{c}} \\
(-4.848)\end{array}$ & $\begin{array}{l}-5.658^{\mathrm{c}} \\
(-4.542)\end{array}$ \\
\hline $\mathrm{N}-\mathrm{Obs}$ & 353 & 342 & 333 \\
\hline R-sq & $\begin{array}{c}0.363 \\
\mathrm{~F}(8,335)=12.02\end{array}$ & $\begin{array}{c}0.419 \\
\mathrm{~F}(17,324)=13.53\end{array}$ & $\begin{array}{c}0.396 \\
\mathrm{~F}(17,315)=13.92\end{array}$ \\
\hline Prob $>$ F & Prob > F 0.0000 & Prob $>$ F 0.0000 & Prob $>$ F 0.0000 \\
\hline
\end{tabular}

(a) Significativo a $5 \%$; (b) Significativo a $1 \%$; (c) Significativo a $0,1 \%$.

Fonte: Elaboração dos autores. 
Para finalizar a exposição dos modelos LSDV e GMM, a Tabela 4, segue o padrão dos anteriores e apresenta os resultados de estimativas LSDV e GMM para um modelo que inclui somente (e exatamente) as variáveis utilizadas para construção de um modelo de crise binário do tipo LOGIT, a ser exposto adiante. Tal procedimento visa checar a robustez dos testes e do procedimento de análise aqui empregada. Além disso, para os resultados da tabela que segue (Tabela 4), foram utilizados ape- nas aqueles países que apresentaram ao menos um evento de crise no período entre janeiro de 1990 e dezembro de 2002. Em termos práticos, isso significa a inclusão de todos os países das tabelas anteriores, à exceção de Israel e Peru. Os resultados apresentados são semelhantes aos anteriores. Os sinais são esperados, e as variáveis são todas significantes ao nível de $1 \%$, à exceção da taxa de desemprego, significante a $5 \%$. Ademais, os testes evidenciam significância global a um nível de 1\%.

Tabela 4_Estimação considerando as mesmas variáveis do modelo LOGIT

\begin{tabular}{|c|c|c|c|}
\hline Dependente: PMC & ModeloL SDV & Modelo GMM1 & Modelo GMM2 \\
\hline DCB & $\begin{array}{c}8.685 \\
(1.820)\end{array}$ & $\begin{array}{l}12.812^{\mathrm{c}} \\
(3.543)\end{array}$ & $\begin{array}{l}17.303^{c} \\
(5.434)\end{array}$ \\
\hline СРMC & $\begin{array}{l}0.335^{\mathrm{b}} \\
(2.988)\end{array}$ & $\begin{array}{l}0.286^{\mathrm{b}} \\
(2.629)\end{array}$ & $\begin{array}{l}0.252^{\mathrm{a}} \\
(2.351)\end{array}$ \\
\hline DIVRES & $\begin{array}{l}4.283^{c} \\
(5.124)\end{array}$ & $\begin{array}{l}4.443^{c} \\
(5.521)\end{array}$ & $\begin{array}{l}4.282^{\mathrm{c}} \\
(5.512)\end{array}$ \\
\hline LCCEX & $\begin{array}{l}-0.012^{\mathrm{b}} \\
(-2.697)\end{array}$ & $\begin{array}{l}-0.012^{\mathrm{b}} \\
(-2.726)\end{array}$ & $\begin{array}{l}-0.014 \mathrm{~b} \\
(-3.216)\end{array}$ \\
\hline CREDIT & $\begin{array}{l}0.028^{\mathrm{b}} \\
(3.144)\end{array}$ & $\begin{array}{l}0.023^{b} \\
(2.700)\end{array}$ & $\begin{array}{l}0.022^{\mathrm{b}} \\
(2.648)\end{array}$ \\
\hline UR & $\begin{array}{l}0.180^{\mathrm{b}} \\
(2.634)\end{array}$ & $\begin{array}{l}0.165^{\mathrm{a}} \\
(2.390)\end{array}$ & $\begin{array}{l}0.145^{\mathrm{a}} \\
(2.053)\end{array}$ \\
\hline Constante & $\begin{array}{l}-7.386^{c} \\
(-6.899)\end{array}$ & $\begin{array}{l}-7.459 \mathrm{c} \\
(-5.800)\end{array}$ & $\begin{array}{l}-7.120^{c} \\
(-5.498)\end{array}$ \\
\hline N-Obs & 369 & 358 & 349 \\
\hline R-sq & $\begin{array}{c}0.330 \\
F(6,353)=11.63\end{array}$ & $\begin{array}{c}0.391 \\
F(15,342)=12.34\end{array}$ & $\begin{array}{c}0.367 \\
F(15,333)=12.65\end{array}$ \\
\hline Prob $>$ F & Prob $>$ F 0.0000 & Prob $>$ F 0.0000 & Prob $>$ F 0.0000 \\
\hline
\end{tabular}

(a) Significativo a $5 \%$; (b) Significativo a $1 \%$; (c) Significativo a $0,1 \%$.

Fonte: Elaboração dos autores. 


\section{Modelos LOGIT}

Os resultados anteriores evidenciam a importância das variáveis relacionadas às restrições solvência e liquidez. Contudo, uma limitação dos testes até aqui apresentados é a ausência de uma definição precisa de crise financeira. Por hipótese, a pressão financeira, ou pressão no mercado cambial (PMC), apresenta um comportamento anômalo nos momentos de crise e, de fato, há evidências de que, para os conhecidos episódios de crise ocorridos entre janeiro de 1990 e dezembro de 2002, os países estudados apresentaram fortes oscilações (para cima) na variável PMC.

Não obstante essas evidências, do ponto de vista de metodologia econométrica, poder-se-ia avançar se for possível obter uma relação entre as variáveis explicativas e eventos de crise previamente definidos. O primeiro passo é justamente a definição de um comportamento da variável PMC que possa ser classificado como crise. Trata-se da construção de uma variável binária $(0,1)$ cujos valores serão determinados a partir dos desvios de PMC em relação à sua média. Formalmente:

Crise $_{i t}=1$ se $P M C_{i t}=$ maior ou igual a $P M C_{\text {medio }}+(x) D P_{P M C}$

Crise $_{i t}=0$, caso contrário.

Portanto, a variável crise adquire o valor "um" sempre que PMC apresentar um valor superior a sua média acrescida de “ $x$ ” desvios-padrão. Além disso, seguindo Rodrik e Velasco (1999), sempre que houver um evento de crise para dado país, assume-se que, nos três períodos seguintes, no caso, trimestres, a variável dependente adquire valor zero. Com isso, um mesmo evento de crise não é contabilizado mais de uma vez. Visto que os dados aqui utilizados são trimestrais, esse procedimento é imprescindível. Cumpre lembrar que o modelo exclui aqueles países que não apresentarem ao menos um evento de crise. Como já mencionado, da amostra inicial, foram desprezados Israel e Peru.

Adotando 2,33 desvios-padrão, foram obtidos 19 episódios de crise. ${ }^{14} \mathrm{O}$ passo seguinte foi escolher um procedimento econométrico adequado à natureza binária da nova variável explicativa. As análises LOGIT e PROBIT geralmente produzem as mesmas conclusões para um mesmo conjunto de dados, havendo, contudo, uma diferença nas magnitudes dos coeficientes estimados. Como regra de bolso, os coeficientes LOGIT são cerca de 1,8 vez o valor dos coeficientes PROBIT. Portanto, a escolha entre os dois modelos advém, sobretudo, da conveniência do pesquisador. Os resultados obtidos com base em uma análise LOGIT, utilizando a variável binária anteriormente definida, encontram-se na Tabela 5 .

\footnotetext{
14 Ver Apêndice para verificar a lista completa dos episódios de crise.
} 
Tabela 5_Estimação dos Modelos LOGIT

\begin{tabular}{|c|c|c|}
\hline Dependente: Crise & Modelo Logit 1 & Modelo Logit 2 \\
\hline $\mathrm{DCB}$ & $\begin{array}{l}12.067 \\
(1.343)\end{array}$ & $\begin{array}{l}15.677 \\
(1.667)\end{array}$ \\
\hline VARGOV & $\begin{array}{c}0.003 \\
(0.568)\end{array}$ & \\
\hline СРMC & $\begin{array}{c}1.079 \\
(1.667)\end{array}$ & $\begin{array}{c}0.198 \\
(0.447)\end{array}$ \\
\hline DIVRES & $\begin{array}{c}2.139 \\
(1.929)\end{array}$ & $\begin{array}{l}2.307 \mathrm{~b} \\
(2.779)\end{array}$ \\
\hline LCCEX & $\begin{array}{l}-0.057^{\mathrm{a}} \\
(-2.497)\end{array}$ & $\begin{array}{l}-0.036^{a} \\
(-2.115)\end{array}$ \\
\hline CREDIT & $\begin{array}{c}0.084 \\
(1.181)\end{array}$ & $\begin{array}{l}0.132^{\mathrm{a}} \\
(2.091)\end{array}$ \\
\hline VARCPI & $\begin{array}{c}0.273 \\
(0.657)\end{array}$ & \\
\hline UR & $\begin{array}{l}1.394^{\mathrm{a}} \\
(2.222)\end{array}$ & $\begin{array}{l}0.763^{\mathrm{a}} \\
(2.236)\end{array}$ \\
\hline Log-Verossimilhanca & -13.3960 & -25.7607 \\
\hline N-Obs & 197 & 299 \\
\hline PseudoR-sq & 0.504 & 0.355 \\
\hline LRtest & 27.277 & 28.382 \\
\hline p-valorLRtest & 0.001 & 0.000 \\
\hline
\end{tabular}

(a) Significativo a $5 \%$; (b) Significativo a $1 \%$; (c) Significativo a $0,1 \%$.

Fonte: Elaboração dos autores.

Baseando-se nos testes realizados anteriormente, uma primeira versão das estimativas LOGIT (LOGIT 1) testou a variável dependente (Crise) utilizando um modelo completo, em que as variáveis de interesse, relacionadas às restrições de sol- vência e liquidez (LCCEX e DIVRES), foram testadas controlando pelo conjunto de variáveis macroeconômicas anteriormente citadas. Os sinais dos coeficientes estimados estão de acordo com o esperado, à exceção da variável que captura o risco político 
(VARGOV), que apresenta um sinal positivamente relacionado à crise, o que é inesperado pelo fato de que maiores valores de VARGOV associam-se a melhores classificações de risco.

Contudo, a variável proxy de risco político (VARGOV) não é significativa a nenhum dos níveis considerados, inclusive a 10\%. Apenas a variável LCCEX, relativa à restrição de solvência, é significativa a um nível de $1 \%$. Considerando um nível de $5 \%$, a variável DIVRES, que captura a restrição de liquidez, e a taxa de desemprego (UR) são significativas. A variável que mensura o contágio (CPMC) é significativa a um nível de $10 \%$. O teste LR e o p-value correspondente sugerem significância global a um nível de $1 \%$. A Tabela 5, apresentada acima, traz também o valor do pseudo R quadrado. O termo "pseudo" refere-se ao fato de não haver, para modelos não-lineares, um equivalente direto do $\mathrm{R}$ quadrado tradicional. Trata-se de uma medida de melhoria no modelo com a inclusão das variáveis independentes, se comparado a um modelo que contém apenas o intercepto.

Uma segunda estimativa LOGIT (LOGIT2) foi feita a partir da exclusão da variável de risco político e de variação da taxa de inflação ao consumidor (VARCPI). Os sinais dos coeficientes obtidos são esperados e, à exceção da variável de contá- gio, todas as demais são significativas a um nível de $10 \%$, sendo que as variáveis de especial interesse deste estudo, o saldo em conta-corrente em relação às exportações (LCCEX) e a dívida de curto prazo em relação às reservas internacionais (DIVRES), são significativas a 5\%, assim como os controles macroeconômicos dados pelo crédito bancário ao setor privado (CREDIT) e a taxa de desemprego (UR). Novamente, o teste LR e o $p$-value correspondente sugerem significância global a um nível de $1 \%$.

O caminho percorrido pela análise empírica se iniciou com a introdução de variáveis que capturassem os fundamentos relativos às restrições de solvência e liquidez ao modelo proposto por Pereira e Seabra (2004). Em todos os testes realizados, os sinais dessas variáveis estiveram em conformidade com a abordagem teórica. Melhoras no saldo em conta-corrente em relação às exportações têm efeito positivo sobre a relação entre dívida externa e exportação, afetando negativamente a variável explicativa PMC. Já um aumento do endividamento de curto prazo em relação às reservas internacionais retrata o grau de fragilidade da economia e o predomínio de unidades financeiras especulativas, afetando positivamente PMC. Além disso, a importância das restrições acima é corroborada com a 
introdução de variáveis macroeconômicas recomendadas pela literatura.

Permanece significativo nos testes empíricos o coeficiente da variável de contágio (CPMC) em um resultado semelhante àquele obtido por Pereira e Seabra (2004). Dado o avanço do processo de abertura financeira, que constitui o outro lado da moeda da estratégia de captação de poupança externa, intensificaram-se as inovações financeiras, sobretudo visíveis nas operações internacionais no mercado de derivativos. Como decorrência, há um maior incentivo para aumentar o grau de endividamento.

Por exemplo, em uma operação de derivativos de crédito, um banco coreano pode fornecer carregar o risco de uma empresa tailandesa, que originalmente havia realizado uma operação de crédito com um banco alemão. Então, problemas nessa empresa atravessam as fronteiras e afetam o banco coreano, em um típico exemplo de contágio. Portanto, uma maior pressão financeira em dado país pode contagiar as estruturas patrimoniais das instituições financeiras e do próprio Banco Central de outro país.

O principal avanço em relação a testes anteriores diz respeito à definição formal do evento "crise". Na primeira versão (LOGIT1), fato relevante parece ser o sinal inesperado da variação do risco político (VARGOV). Mesmo assim, os resultados indicam significância de LCCEX e DIVRES a um nível de 5\%. Uma nova estimativa (LOGIT2), com a supressão de VARGOV, mantém a significância de LCCEX e DIVRES na presença dos demais controles.

Sobre o sinal da variável de risco político,VARGOV, uma possibilidade seria o fato de essa variável apresentar, de maneira global, oscilação relativamente pequena. Isso decorre do tipo de classificação de risco, que tem natureza de médio e longo prazo, não se alterando, necessariamente, com as oscilações de mercado, ao contrário de classificações de risco marked-to-market. Ademais, repetidas vezes, tais classificações são defasadas em relação aos eventos associados à crise. No caso da crise asiática, por exemplo, há evidências de que várias agências de rating só alteraram sua classificação após a eclosão da crise propriamente dita. Portanto, esses ratings divulgados seriam reativos à crise que poderia estar comprometendo a causalidade esperada no caso de uma variável dependente binária.

Em suma, os dados dão suporte empírico às considerações teóricas anteriores e evidenciam os efeitos das restrições de solvência e liquidez, deterioradas pelo acúmulo de déficits em conta-corrente, sobre a probabilidade de ocorrência de crises financeiras. O encadeamento da exposição aqui realizada objetivou demonstrar a pro- 
gressão obtida com base nas diversas estimativas, com um aprimoramento gradual dos modelos, de forma a incorporar variáveis relevantes de controle que fornecessem maior robustez aos resultados estimados. A definição formal de crise, gerando uma variável binária, consistiu no passo final do protocolo de análise e produziu, para as variáveis-chave do modelo, resultados alinhados com as estimativas anteriores.

\section{4_Conclusão}

Ao contrário do que afirma a teoria econômica convencional, não são os déficits públicos, mas os déficits em conta-corrente continuados que causaram as crises de balanço de pagamentos no período aqui examinado. Déficits públicos podem ser causadores de crise quando a hipótese dos déficits gêmeos se confirma fato que nem sempre sucede, porque nem sempre a taxa de câmbio prevalente é a taxa de câmbio de equilíbrio. A taxa de câmbio pode permanecer sobreapreciada durante um tempo relativamente grande porque os credores externos, atraídos pelos altos rendimentos de seus capitais nos países em desenvolvimento, subestimam as restrições de liquidez e solvência, e essa taxa pode permanecer permanentemente sobreapreciada se o país sofrer da doença holandesa (2008a). Dessa for$\mathrm{ma}$, a política de recorrer à poupança externa para crescer, além de implicar uma taxa geralmente elevada de substituição da poupança interna pela externa, não resultando, portanto, em aumento proporcional dos investimentos, tende a causar crises financeiras - especificamente, crises de balanço de pagamentos.

A probabilidade de crise aumenta em decorrência dos efeitos do crescente endividamento externo sobre as restrições de solvência e liquidez. Para países altamente endividados, a captação de poupança externa tende a afetar, sobretudo, a restrição de solvência, enquanto países menos endividados tendem a ser afetados por meio da restrição de liquidez.

Nos testes realizados, os sinais das variáveis relacionadas à solvência e liquidez foram significativos, enquanto, nesses mesmos testes, a variável fiscal não foi significativa. Portanto, os dados dão suporte empírico às considerações teóricas iniciais e evidenciam o fato de que a estratégia de uso da poupança externa acabou produzindo as crises financeiras pelo acúmulo de déficits em conta-corrente, não pelo desequilíbrio fiscal, conforme a teoria dos déficits gêmeos.

Como comentário final, este trabalho confirma a tese de um de seus autores 
(Bresser-Pereira, 2008b e 2009b, cap. 4) segundo a qual existe em todos os países em desenvolvimento a tendência à sobreapreciação da taxa de câmbio. Segundo essa tese que foi desenvolvida pelo autor depois que este trabalho foi concebido, mas que é com ele plenamente coerente, a taxa de câmbio não é equilibrada pelo mercado, mas através de crises. Existem fatores estruturais (a doença holandesa e taxas de lucro e de juros mais elevadas) agravados por causas de política econômica (política de crescimento com poupança externa, política de aprofundamento financeiro, política de âncora cambial, política para resolver o problema do dos "dois hiatos", e o populismo cambial) que levam a taxa de câmbio nos países em desenvolvimento a se apreciar até o ponto em que um déficit em contacorrente crescente e elevado leva os credores externos do país a suspender a rolagem da dívida externa e, assim, ao desencadeamento da crise de balanço de pagamentos. Essas crises têm, portanto, um duplo elemento endógeno ou estrutural e são acentuadas por políticas econômicas. Se tais políticas não forem evitadas, e se os fatores estruturais não forem neutralizados, a taxa de crescimento do país será muito prejudicada; o país sofrerá crises de balanço de pagamentos recorrentes. 


\section{Referências bibliográficas}

ALVES JR., A. J.; de PAULA, L. F. Vulnerabilidade externa e ataques especulativos: a experiência brasileira recente. In: De PAULA, L. F.; FERRARI, F. F. Globalização financeira, ensaios de macroeconomia aberta. Petrópolis: Vozes, 2004.

ARESTIS, P.; GLICKMAN, M. Financial crisis in Southeast Asia: dispelling illusion the Minskyan

Way. Cambridge Journal of Economics, n. 26, p. 232-260, 2002.

BELLUZZO, L. G.;

COUTINHO, L. Financeirização da riqueza, inflação de ativos e decisões de gasto em economias abertas. Revista Economia e Sociedade, n. 11, 2004.

BHAGWATI, J. In defense of globalization: a council on foreign relations book. Oxford University Press, 2004

BRESSER-PEREIRA, Luiz

Carlos. Financiamento para o subdesenvolvimento: o Brasil e o Segundo Consenso de Washington. In: CASTRO, Ana Célia (Org.). Desenvolvimento em debate: painéis do desenvolvimento brasileiro, Rio de Janeiro: Mauad/BNDES, v. 2, 2002. p. 359-398.
BRESSER-PEREIRA, Luiz

Carlos. Exchange rate: fix, float, or manage it?. Prefácio a Mathias Vernengo (Org.). Monetary integration and dollarization: no panacea. Cheltenham: Edward Elgar, XIII-XIX, 2004

BRESSER-PEREIRA, Luiz Carlos. Dutch disease and its neutralization: a Ricardian approach, Brazilian Journal of Political Economy, v. 28, n. 1, p. 47-71, 2008a.

\section{BRESSER-PEREIRA, Luiz}

Carlos. A tendência à sobre apreciação da taxa de câmbio. In: FÓRUM DE ECONOMIA DA FUNDAÇÃO GETÚlIO VARGAS, 5., 2008, São Paulo. Trabalbo apresentado... São Paulo: EESP, set. 2008b. Disponível em:

$<$ http://www.bresserpereira. org.br $>$.

\section{BRESSER-PEREIRA, Luiz}

Carlos. Mondialisation et Compétion. Paris: La Découverte, 2009a.

BRESSER-PEREIRA, Luiz

Carlos. Os dois métodos e o coração da teoria econômica. Revista de Economia Política, v. 29, n. 1, 2009b.
BRESSER-PEREIRA, Luiz Carlos; GALA, Paulo. Por que a poupança externa não promove o crescimento. Revista de Economia Política, n. 27. n. 1, p. 3-19, jan. 2007.

\section{BRESSER-PEREIRA, Luiz} Carlos; NAKANO, Yoshiaki. Economic growth with foreign savings? Trabalho apresentado ao Seventh International Post Keynesian Workshop. Kansas City, Mi., 30 jun. 2002. Disponível em: $<$ http://www.bresserpereira.org. br>. (Traduzido para o português, "Crescimento econômico com poupança externa?” Revista de Economia Política, v. 22, n. 2, p. 3-27, abr. 2003).

CHANG, H-Joon. Korea: the misunderstood crisis. World Development, v. 26, n. 8, Tigers in Trouble, Zed Press, 1998. [reprinted in Jomo, S.K. (ed.)].

CHANG, R.; VELASCO, A. The Asian liquidity crisis. Federal Reserve Bank of Atlanta, July 1998. (Working Paper, n. 98)

CHINN, M. Before the fall: were East Asian currencies overvalued? NBER, 1997. (Working Paper, n. 6491).
CINTRA, M. A. C.; PRATES, D.

M. Os fluxos de capitais internacionais para o Brasil desde os anos 90. 2004.

Disponível em: < http://www.rls org.br/publique/media/ Controle_Cintra_Prates.pdf $>$.

Acesso em: 18 ago. 2006.

CORDEN, W. M. Economic policy, exchange rates, and the international system. Oxford: Oxford University Press, and Chicago: The University of Chicago Press, 1994.

EATWELL, J.; TAYLOR, L.

Global finance at risk: the case for international regulation. New York: The New Press, 2000

EICHENGREEN, B. Capital account liberalization: what do cross-country studies tell us? The World Bank Economic Review, v. 15, n. 3, p. 341-365, 2001

EICHENGREEN, B.; ROSE, C. Staying afloat when the wind shifts: external factors and emerging-market banking crises. 1998. (Trabalho não publicado). 
EICHENGREEN, B. et al. speculative attacks on pegged exchange rates: an empirical exploration with special reference to the European monetary system. NBER, 1994. (Working Paper, n. 4898).

\section{EICHENGREEN, B.;}

FISHLOW, A. Contending with capital flows: what is different about the 1990s? In: KAHLER, Miles (ed.). Capital flows and financial crises. Cornell University Press, 1998. p. 23-68.

\section{EDWARDS, S. Does current} account matter? Florida, Jan. 2000. (Paper prepared for the NBER conference on Crisis Prevention).

\section{EDWARDS, F. R.; MISHKIN, F.}

The decline of traditional banking: implications for financial estability and regulatory policy. Federal Reserve Bank of New York, Economic Policy Review, p. 27-45, July 1995.

FELDSTEIN, M.; HORIOKA, C. Domestic savings and international capital flows. Economic Journal, v. 90, n. 358, p. 314-229, June, 1980.

\section{FINANCIAL TIMES. Country} Classification. 2006. Atualização disponível em:

$<$ http://www.ft.com>.
FLOOD, R. P.; GARBER, P. M. Collapsing exchange-rate regimes, some linear examples. Journal of International Economics, v. 17, p. 1-13, 1984.

\section{GOLDFAJN, I.; VALDÉS, R.}

O. Liquidity crises and the international financial architecture. Jul. 1999. 28p.

GOLDFAJN, I. The swings in capital flows and the Brazilian crisis. Abr. 2000. 39p. (Texto não publicado).

GONZALEZ, Lauro. Crises financeiras recentes: revisitando as experiências da América Latina e da Ásia. São Paulo: Escola de Economia de São Paulo, jun. 2007.

KALECKI, M. Theory of economic dynamics. 2 ed. New York: Modern Reader Paperbacks, 1965.

KAMINSKY, G. L. C. M.; REINHART, C. M. The twin crises: the causes of banking and balance of payments problems. American Economic Review, v. 289, 1998.

KEYNES, J. M. Teoria geral do emprego, do juro e da moeda. São Paulo: Nova Cultural, 1985.

\section{KINDLEBERGER, Charles.}

Manias, pânico e crashes: um histórico das crises financeiras. Rio de Janeiro: Nova Fronteira, 2000. (Trad. da ed. americana de 1996).
KRUGMAN, P. A Model of balance of payments crises. Journal of Money Credit and Banking, v. 11,1979

KRUGMAN, P. What Happened to Asia? 1998. Mimeo.

\section{MAGALHÃES, J. R. C.}

Liberalização financeira internacional e crescimento econômico. IPEA, dez. 2002. (Texto para discussão, n. 932).

MIRANDA, M. C. Crises cambiais e ataques especulativos no Brasil. 2002. (Textos para Discussão, n. 266).

MINSKY, H. P. The instability of capitalism. Journal of Economic Issues, v. 14, June 1980.

MINSKY, H. P. Stabilizing an Unstable Economy. New Haven: Yale University Press, 1986.

NEFTCI, S. FX short positions, balance sheets and financial turbulence: an interpretation of the Asian financial crisis. In: EATWELL, J.; TAYLOR, L. (eds.). International Capital Markets. Oxford University Press, 2002.

OBSTFELD, M. Rational and self-fulfilling balance-of-payments crises. American Economic Review, v. 76, p. 72-81, 1986.

OBSTFELD, M. The logic of currency crises. Cabiers Economiques et Monetaires, v. 43, 1994.
ÖTKER, Inci; PAZARBASIOGLU, Ceyla. Speculative attacks and currency crises: the Mexican experience. Washington: Fundo Monetário Internacional, 1995. (IMF Working Paper 95/112).

PALMA, G. The magical realism of Brazilian economics: how to create a financial crisis by trying to avoid one. In: EATWELL, J.; TAYLOR, L. (eds.). International Capital Markets, Oxford University Press, 2002a.

PALMA, G. The three routes to financial crises: the need for capital controls. In: EATWELL, J.; TAYLOR, L. (eds.).

International Capital Markets. Oxford University Press, 2002b.

PEREIRA, A. P. M.; SEABRA, F. Crises cambiais e bancárias na década de 1990: uma análise de painel aplicada a mercados emergentes. In: ENCONTRO NACIONAL DE ECONOMIA, 32., João Pessoa, 2004. Anais... João Pessoa: ANPEC, 2004.

QUINN, D. Correlates if changes in international finance regulation. American Political Science Review, v. 91, n. 3, p. 531-551, 1997.

RADELET, S.; SACHS, J. The onset of the East Asian financial crisis. In: KRUGMAN, P. (Ed). Currency Crises. U. of Chicago Press, 1998. 
REISEN H. Sustainable and excessive current account deficits. OECD - Development Centre, 1998. (Working Paper, n. 132)

\section{REZENDE. F. Déficits}

gêmeos e poupança nacional: abordagem convencional e pós keynesiana. Belo Horizonte: UFMG/Cedeplar, 2005.

(Texto para discussão, n. 256).

ROBICHEK, E. Walter. Some reflections about external public debt management. Estudios Monetarios VII, Banco Central de Chile, 1981.

RODRIK, D. Who needs capital-account convertibility? In: KENEN, P. (ed.). Should the IMF pursue capital-account convertibility? Essays in International Finance, Princeton University Press, n. 207, May 1998.

RODRIK, D.; VELASCO, A. Short-term Capital Flows. NBER, 1999. (Working Paper, n. 7364).

ROUBINI, N.; SETSER, B. Bailouts or bail-ins: responding to financial crises in emerging markets. Paperback.

Institute for International Economics. 2005.

SACHS, J. The current account and macroeconomic adjustment in the1970s. Brookings Papers on Economic Activity, n. 1, 1981.
SANT'ANA, A. Crises cambiais: uma análise à luz da experiência brasileira. 2002. Dissertação (Mestrado) EAESP-FGV, 2002.

SCHWARTSMAN A. A crise fiscal e o ajuste fiscal. Revista de Economia Politica, v. 19, n. 1, jan./mar. 1999.

SINGH. Asian Capitalism and the Financial Crisis. In: EATWELL, J.; TAYLOR, L. (eds.).

International Capital Markets.

Oxford University Press, 2002.

TAYLOR, L. Capital market crises: liberalisation, fixed exchange rates and market-driven destabilization. Cambridge Journal of Economics, v. 22, p. 663-676, 1998.

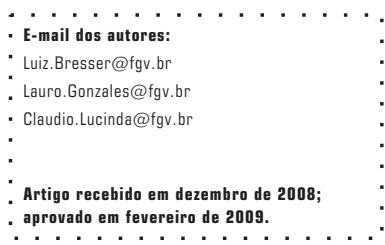


Apêndice

Episódios de crise: Modelo LOGIT

\begin{tabular}{|c|c|c|}
\hline & País & Período \\
\hline 1 & Argentina & 1990Q1 \\
\hline 2 & Argentina & 2002Q1 \\
\hline 3 & Brasil & 1991Q4 \\
\hline 4 & Coreia & 1997Q4 \\
\hline 5 & Equador & 1992Q3 \\
\hline 6 & Equador & 1998Q3 \\
\hline 7 & Equador & 1999Q4 \\
\hline 8 & Filipinas & 1997Q3 \\
\hline 9 & Indonésia & 1997Q4 \\
\hline 10 & México & 1994Q2 \\
\hline 11 & República Tcheca & 1997Q2 \\
\hline 12 & Rússia & 1998Q3 \\
\hline 13 & Tailândia & 1997Q3 \\
\hline 14 & Turquia & 1991Q1 \\
\hline 15 & Turquia & 1994Q1 \\
\hline 16 & Turquia & 2001Q1 \\
\hline 17 & Venezuela & 1994Q2 \\
\hline 18 & Venezuela & 1998Q3 \\
\hline 19 & Venezuela & 2002Q1 \\
\hline
\end{tabular}

Fonte: Elaboração dos autores. 